\title{
Serial follow-up of malaria-induced splenic infarction: A case report
}

\author{
Sung Hyun Kim, Hong Sung Jung, and Sejin Park
}

\author{
Department of Surgery, Armed Forces Capital Hospital, Seongnam, Korea
}

\begin{abstract}
Malaria shows various clinical manifestations from mild fever to death depending on the Plasmodium species. Among the complications, reports of malaria-associated splenic infarctions are rare. Here we present a case in which a man suffered from malaria-induced splenic infarction with serial follow-up. A 28-year-old man who served in the military near the Korean Demilitarized Zone (DMZ) was referred to the emergency room for fever beginning 1 week ago. He suffered upper abdominal pain for 2 days. At the time of his visit, he experienced a fever spiking up to $39.8^{\circ} \mathrm{C}$. In the patient's computed tomography (CT) test, splenomegaly with low attenuation density suggesting splenic infarction and hepatomegaly was shown. Because red blood cells infected by a plasmodium species were shown in a peripheral blood smear, he was admitted for malaria infection. The patient was given oral chloroquine on the day of admission and on hospital day (HOD) 3, Plasmodium vivax was detected in his malaria PCR test. After conservative management, the patient's condition improved. The patient was discharged on HOD 15 without any symptoms. At this time, the patient's spleen size decreased to the upper limit size of normal according to an ultrasonography. After that, the patient visited the outpatient department. Although low attenuation density still appeared in the following CT on HOD 30, a subsequent ultrasonography on HOD 60 did not show any specific finding. Although malaria-induced splenic infarction is still rare, this rate may increase. Most of the cases can be treated without surgery. (Ann Hepatobiliary Pancreat Surg 2020;24:239-242)
\end{abstract}

Key Words: Malaria; Plasmodium vivax; Splenic infarction; Conservative treatment; Follow-up studies

\section{INTRODUCTION}

Malaria is a protozoan disease transmitted by mosquitos. This disease shows various clinical manifestations from mild fever to death according to the Plasmodium species. Sometimes malaria is accompanied by severe complications such as cerebral malaria, renal failure, jaundice or abnormal bleeding. ${ }^{1}$ Among the complications, reports of malaria-associated splenic infarctions are rare. ${ }^{2}$ Fortunately, most of the cases reported that patients recovered with conservative management without surgery. ${ }^{3}$ However, most of the case reports did not describe the patients' status after discharge from the hospital. Here we present a case in which a man suffered from malaria-induced splenic infarction with serial follow-up.

\section{CASE}

A 28-year-old man fulfilling his military service near the Korean Demilitarized Zone (DMZ) and did not have oversea travel records within 6 months was referred to the emergency room for fever which began 1 week ago. He suffered upper abdominal pain for 2 days. His last taking of anti-malarial drug for chemoprophylaxis was 2 years ago. At the time of his visit to the emergency room, he experienced a fever spiking up to $39.8^{\circ} \mathrm{C}$. Blood pressure was $131 / 74 \mathrm{~mm} \mathrm{Hg}$, respiratory rate was 16 breaths $/ \mathrm{min}$ and heart rate was 87 beats/min. His numeric pain rating scale was 3 . However, abdominal palpation revealed no tenderness. An initial blood sample objectified the following results: white blood cell count of $8870 / \mu 1$, C-reactive protein level of $11.43 \mathrm{mg} / \mathrm{dl}$, platelet count of $57000 / \mu 1$, total bilirubin level of $1.8 \mathrm{mg} / \mathrm{dl}$, aspartate aminotransferase (AST) level of $83 \mathrm{IU} / \mathrm{L}$, alanine aminotransferase (ALT) level of $181 \mathrm{IU} / \mathrm{L}$, alkaline phosphatase level of $249 \mathrm{IU} / \mathrm{L}$, and gamma-glutamyl transpeptidase level of 70 IU/L. In the computed tomography (CT), hepatomegaly was shown and splenomegaly (about $16 \mathrm{~cm}$ ) with low at-

Received: January 29, 2020; Revised: January 30, 2020; Accepted: January 31, 2020

Comesponding author: Sejin Park

Department of Surgery, Armed Forces Capital Hospital, 177 Saemaeul-ro, Seongnam 13574, Korea

Tel: +82-31-902-6249, Fax: +82-31-725-5114, E-mail: sjppp@naver.com

Copyright (C) 2020 by The Korean Association of Hepato-Biliary-Pancreatic Surgery

This is an Open Access article distributed under the terms of the Creative Commons Attribution Non-Commercial License (http://creativecommons.org/ licenses/by-nc/4.0) which permits unrestricted non-commercial use, distribution, and reproduction in any medium, provided the original work is properly cited. Annals of Hepato-Biliary-Pancreatic Surgery • pISSN: 2508-5778 - elSSN: 2508-5859 
tenuation density suggesting splenic infarction was shown (Fig 1A, B). Because red blood cells infected by plasmodium species were shown in the peripheral blood smear, he was admitted with malaria infection. In addition, because there was no definite tenderness around the patient's abdomen from physical examination, we decided to perform conservative care without surgical treatment. The patient was given oral chloroquine $(25 \mathrm{mg} / \mathrm{kg}$ in 3 days) on the day of admission. On hospital day (HOD) 3, P. vivax was detected in the patient's malaria PCR test.

After conservative management, the patient's condition improved. His fever subsided on HOD 3. Although AST and
ALT increased up to about 200 on HOD 4, (AST: 151 IU/L, ALT: 217 IU/L) his laboratory findings were getting better (Table 1). The patient was discharged on HOD 15 without any symptoms. At this time, another malaria PCR test showed negative findings and the patient's spleen size decreased to the upper limit of normal size $(13 \mathrm{~cm})$ in the abdominal ultrasonography (Fig. 1C). At discharge, oral primaquine (15 mg/day) was prescribed. The patient visited the outpatient department on HOD 30 and 60, respectively. Although low attenuation density still appeared in the following CT, the lesion decreased compared to initial image and the size of the spleen decreased
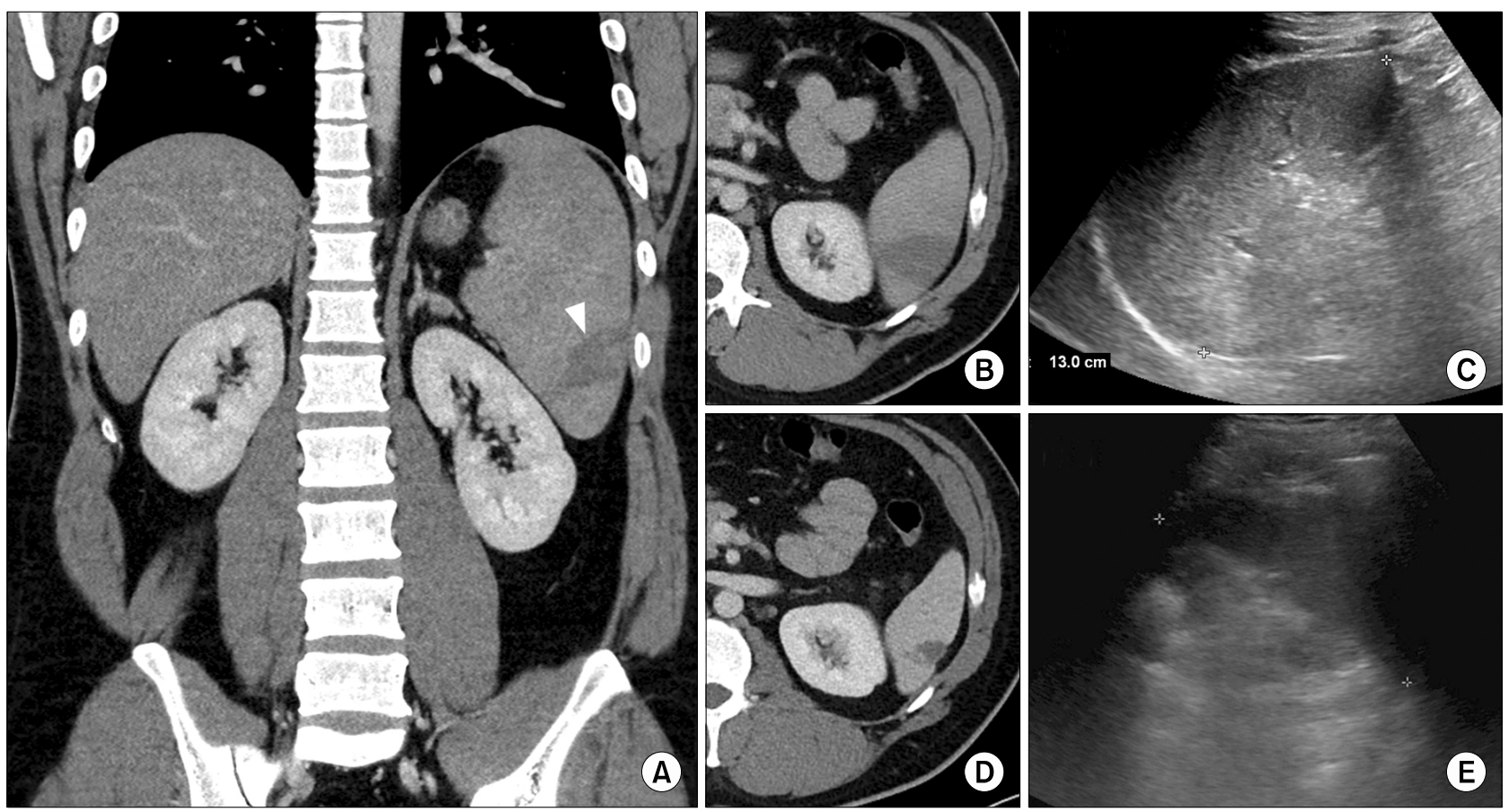

Fig. 1. Serial follow-up image studies of the patient. (A) Initial: hepatomegaly and splenomegaly with focal splenic infarction (white wedge), (B) Initial: focal low attenuation density at spleen, (C) HOD 15: decreased spleen size to upper limit of normal, (D) HOD 30: decreased pathologic lesion compared to initial image, (E) HOD 60: decreased spleen size to normal range.

Table 1. Biological parameters of the patient

\begin{tabular}{lcccccccccc}
\hline \multicolumn{1}{c}{ HOD (day) } & 1 & 2 & 3 & 4 & 5 & 8 & 12 & 15 & 30 & 60 \\
\hline WBC $\left(10^{3} / \mu \mathrm{l}\right)$ & 8.87 & 8.36 & 7.71 & 8.01 & 8.49 & 10.43 & 7.62 & 8.59 & 6.29 \\
Neutrophil $(\%)$ & 48.7 & 43.0 & 34.6 & 30.4 & 30.8 & 53.9 & 43.4 & 51.4 & 40.3 \\
Plt $\left(10^{3} / \mu \mathrm{l}\right)$ & 57 & 80 & 79 & 114 & 168 & 292 & 305 & 271 & 253 \\
CRP (mg/dl) & 11.43 & 9.12 & & & 2.53 & 0.45 & & & & \\
T. bil (mg/dl) & 1.8 & 1.1 & 1.3 & 1.1 & 0.6 & 0.8 & 1.0 & 0.9 & 0.8 \\
AST (IU/L) & 83 & 69 & 93 & 151 & 126 & 79 & 42 & 44 & 33 & 45 \\
ALT (IU/L) & 181 & 149 & 167 & 217 & 216 & 213 & 116 & 86 & 72 & 35 \\
ALP (IU/L) & 249 & 240 & 212 & 241 & 269 & 244 & 240 & 266 & 256 \\
\hline
\end{tabular}

HOD, hospital day; WBC, white blood cell; Plt, platelet; CRP, C-reactive protein; T. bil, total bilirubin; AST, aspartate amiotransferase; ALT, alanine transaminase; ALP, alkaline phosphatase 
to normal range on HOD 30 (Fig. 1D). On HOD 60, the patient's ultrasonography did not show any specific finding and his clinical examination and liver profile was normal (Fig. 1E).

\section{DISCUSSION}

Although the Republic of Korea (ROK) once was declared malaria free by the World Health Organization, malaria reemerged in 1993 and is still prevalent near the DMZ. ${ }^{4,5}$ One reason of reemergence is climate change. Some articles showed that temperature likely played a role in the dynamics of malaria transmission in the ROK. ${ }^{4}$ Another reason is the geopolitical characteristic of ROK. In ROK, vector control near the DMZ is difficult due to Democratic People's Republic of Korea. ${ }^{6}$

To prevent the spread of malaria, ROK initiated chemoprophylaxis with anti-malarial drug (hydroxychloroquine and primaquine phosphate) among military personnel assigned to areas at high risk for malaria (mainly near $\mathrm{DMZ})^{7}$ As a result, the incidence of malaria in the ROK has decreased. However, one interesting point is that severe malaria cases increased significantly over time. ${ }^{8}$ Although, the exact reason for the increase is uncertain, some studies explain this feature is due to resistance of anti-malarial drug or a change in the $P$. vivax strain., With this trend, malaria-induced splenic infarction has increased.

Although the pathogenesis is not clearly revealed, several factors such as vascular congestion and occlusion, hypercoagulable state and anemic hypoxia are suggested to induce malaria-induced splenic infarction. ${ }^{2}$ Therefore, this infarction is a transient feature. The patient condition improved resulting in better flow of the spleen. Actually, without splenic rupture, most of the malaria-induced splenic infarction could be cured with only conservative care. In our case, improving splenomegaly and decreasing low attenuation density were shown as time went on. However, if the spleen was ruptured, some patients should undergo a splenectomy, which may lead to a mortality rate of up to $15 \%{ }^{10}$ Therefore, it appears to be important to detect the splenic infarction and treat the malaria early. In the meantime, surgeons should pay attention to the probability of spleen rupture that might require splenectomy.

To sum up, with the change of the times, malaria-in- duced splenic infarction could increase and many surgeons could experience similar cases. Our case is a typical case that reflects the background of recent ROK and is meaningful to serially show the clinical course of the patient who experienced malaria-induced splenic infarction with various imaging modalities.

In conclusion, although malaria induced splenic infarction is still rare the rate might increase. Therefore, surgeons should be interested in its complications and clinical manifestations to make a decision for the patients.

\section{CONFLICT OF INTEREST}

No potential conflict of interest relevant to this article was reported.

\section{ORCID}

Sung Hyun Kim: https://orcid.org/0000-0001-7683-9687

Hong Sung Jung: https://orcid.org/0000-0003-0477-8242

Sejin Park: https://orcid.org/0000-0003-4462-2517

\section{AUTHOR CONTRIBUTIONS}

Conceptualization: SHK, SP. Data curation: SHK. Visualization: SHK. Writing - original draft: SHK. Writing - review \& editing: HSJ.

\section{REFERENCES}

1. White NJ, Pukrittayakamee S, Hien TT, Faiz MA, Mokuolu OA, Dondorp AM. Malaria. Lancet 2014;383:723-735.

2. Hwang JH, Lee CS. Malaria-induced splenic infarction. Am J Trop Med Hyg 2014;91:1094-1100.

3. Norman FF, Rojas-Marcos J, Hermida-Donate JM, MongeMaillo B, Perez-Molina JA, López-Vélez R. Splenic infarction and malaria. Trans R Soc Trop Med Hyg 2014;108:455-460.

4. Linthicum KJ, Anyamba A, Killenbeck B, Lee WJ, Lee HC, Klein TA, et al. Association of temperature and historical dynamics of malaria in the Republic of Korea, including reemergence in 1993. Mil Med 2014;179:806-814.

5. World Health Organization. Synopsis of the world malaria situation, 1979. Wkly Epidemiol Rec 1981;56:145-149.

6. Chang KS, Yoo DH, Ju YR, Lee WG, Roh JY, Kim HC, et al. Distribution of malaria vectors and incidence of vivax malaria at Korean army installations near the demilitarized zone, Republic of Korea. Malar J 2016;15:259.

7. Yeom JS, Ryu SH, Oh S, Choi DH, Song KJ, Oh YH, et al. Evaluation of anti-malarial effects of mass chemoprophylaxis in the Republic of Korea army. J Korean Med Sci 2005;20:707712 . 
8. Park SY, Park YS, Park Y, Kwak YG, Song JE, Lee KS, et al. Severe vivax malaria in the Republic of Korea during the period 2000 to 2016. Travel Med Infect Dis 2019;30:108-113.

9. Lim HS, Im JS, Cho JY, Bae KS, Klein TA, Yeom JS, et al. Pharmacokinetics of hydroxychloroquine and its clinical im- plications in chemoprophylaxis against malaria caused by Plasmodium vivax. Antimicrob Agents Chemother 2009;53:1468-1475.

10. Imbert $P$, Rapp C, Buffet PA. Pathological rupture of the spleen in malaria: analysis of 55 cases (1958-2008). Travel Med Infect Dis 2009;7:147-159. 